\title{
Long-term health effects of early life exposure to tetrachloroethylene (PCE)-contaminated drinking water: a retrospective cohort study
}

\author{
Ann Aschengrau ${ }^{1 *}$, Michael R Winter ${ }^{2}$, Veronica M Vieira ${ }^{3}$, Thomas F Webster ${ }^{4}$, Patricia A Janulewicz ${ }^{4}$, \\ Lisa G Gallagher', Janice Weinberg ${ }^{5}$ and David M Ozonoff ${ }^{4}$
}

\begin{abstract}
Background:

While adult exposure to PCE is known to have toxic effects, there is little information on the long-term impact of prenatal and early childhood exposure. We undertook a retrospective cohort study to examine the effects of their early life exposure to PCE-contaminated drinking water. This retrospective cohort study examined whether prenatal and early childhood exposure to PCE-contaminated drinking water influenced the risk of a variety of chronic conditions among adults who were born between 1969 and 1983 in the Cape Cod area of Massachusetts.
\end{abstract}

Methods: Eight hundred and thirty-one participants with prenatal and early childhood PCE exposure and 547 unexposed participants were studied. Individuals completed questionnaires to gather information on demographic characteristics, chronic conditions, and other sources of solvent exposure. The location of residences from birth through 1990 were used to estimate PCE exposure with U.S. EPA's water distribution system modeling software (EPANET) modified to incorporate a leaching and transport model.

Results: No associations were observed between early life PCE exposure and current occurrence of obesity, diabetes, cardiovascular disease, hypertension, color blindness, near- and far sightedness and dry eyes. In contrast, a 1.8-fold increased risk of cancer ( $95 \% \mathrm{Cl}: 0.8,4.0)$ was seen among individuals with any early life exposure. These results were based on 31 participants ( 23 exposed and 8 unexposed) who reported cancers at a variety of anatomical sites, particularly the cervix. A 1.5-fold increase in the risk of epilepsy ( $95 \%$ Cl: 0.6, 3.6, based on 16 exposed and 7 unexposed participants) was also observed among individuals with any early life exposure that was further increased to $1.8(95 \% \mathrm{Cl}: 0.7,4.6)$ among those with exposure at or above the sample median.

Conclusions: These results suggest that the risk of epilepsy and certain types of cancer such as cervical cancer may be increased among adults who were exposed to PCE-contaminated drinking water exposure during gestation and early childhood. These findings should be interpreted cautiously because of the study limitations and confirmed in follow-up investigations of similarly exposed populations with medically-confirmed diagnoses. This relatively young study population should also be monitored periodically for subsequent changes in disease risk.

Keywords: Drinking water, Tetrachloroethylene, Cancer, Epilepsy

\footnotetext{
* Correspondence: aaschen@bu.edu

${ }^{1}$ Department of Epidemiology, Boston University School of Public Health,

Talbot 3E, 715 Albany Street, Boston, MA 02118, USA

Full list of author information is available at the end of the article
}

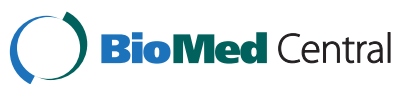

(c) 2015 Aschengrau et al.; licensee BioMed Central. This is an Open Access article distributed under the terms of the Creative Commons Attribution License (http://creativecommons.org/licenses/by/4.0), which permits unrestricted use, distribution, and reproduction in any medium, provided the original work is properly credited. The Creative Commons Public Domain Dedication waiver (http://creativecommons.org/publicdomain/zero/1.0/) applies to the data made available in this article, unless otherwise stated. 


\section{Background}

In 1980 Massachusetts officials found that tetrachloroethylene (PCE) was leaching into public drinking water supplies from a vinyl liner (VL) that had been applied to asbestos cement (AC) water distribution pipes [1]. The lining of vinyl toluene resin was applied in a slurry with PCE as the solvent (Piccotex; Johns-Manville Corporation, Denver, CO). The lining was introduced as a solution to taste and odor problems associated with conventional AC water mains. The PCE was thought to evaporate by the time the pipes were installed; however, sizeable quantities remained and slowly leached into the drinking water supplies.

Surveys estimated that approximately 660 miles of VL/ AC pipes were installed in nearly 100 cities and towns in Massachusetts from 1968 to 1980 . Because the pipes were installed in response to replacement and expansion needs in a town's water system, the contamination pattern was irregular and neighboring residents often had vastly different exposure levels. PCE levels in one town ranged from undetectable to $80 \mu \mathrm{g} / \mathrm{L}$ in water pipes along main streets with high water flow and from 1,600 to $7,750 \mu \mathrm{g} / \mathrm{L}$ in water pipes along dead end streets with low water flow [2].

This specific and unusual source of contamination has since been brought down to what US EPA considers acceptable levels by flushing and bleeding water from the affected pipes, but PCE contamination of public water supplies is common, with adverse health consequences attributed to public water sources contaminated by PCE from landfills and leaking underground storage tanks [3], and dry cleaning facilities [4]. Thus, communitybased PCE exposure remains an important topic of investigation.

Exposure to PCE from drinking water occurs through direct ingestion, dermal exposure during bathing and, because it volatilizes easily, by inhalation during showering, bathing and other household uses. According to the US EPA, PCE is considered "likely to be carcinogenic in humans" by all exposure routes, and to have toxic effects on the central nervous, renal, digestive, immune and hematological systems $[5,6]$. These conclusions were based mainly on animal experiments and human studies of adults exposed in occupational and environmental settings. Few studies have investigated possible health effects among individuals exposed during gestation and early childhood, and most of these studies have examined only health effects during childhood [7-10].

For these reasons, we undertook a population-based retrospective cohort study to determine if prenatal and early childhood exposure to PCE contaminated drinking water had a long-term impact on health. Outcomes previously reported in our study population included mental illness [11], affinity for risky behaviors [12], visual deficits in color discrimination and contrast sensitivity [13], and performance on neuropsychological tests [14]. The current report describes the impact of early life exposure on the risk of cancer, obesity and chronic diseases of the central nervous, visual, cardiovascular, endocrine, and musculoskeletal systems.

\section{Methods}

\section{Selection of study population}

Individuals were eligible for the present study if they were born between 1969 and 1983 to married women living in one of eight Cape Cod, Massachusetts towns known to have some VL/AC pipes in their water distribution system [1]. The exclusion of unmarried women and their children was an approval requirement of the Massachusetts Department of Public Health Privacy and Data Access Office. Eligible individuals were identified by reviewing birth certificates and cross-matching the maternal address and date of birth on the certificate with information collected from water companies on the location and installation year of VL/AC pipes.

To efficiently identify subjects who were likely to be exposed or unexposed, we visually inspected maps depicting the pipe distribution network in the vicinity of the birth address. Subjects were tentatively designated as "exposed" when their birth residence was either directly adjacent to a VL/AC pipe or indirectly adjacent to a pipe connected to a VL/AC pipe with the only possible water flow through VL/AC pipe $(\mathrm{N}=1,910)$. Subjects who were initially designated as "unexposed" were randomly selected from the remaining resident births during this time period and frequency matched to exposed subjects on month and year of birth $(\mathrm{N}=1,928)$.

In addition, 1,202 older siblings of exposed and unexposed subjects were identified if they were born in Massachusetts during 1969-1983. All older siblings were initially considered unexposed during the prenatal period because they were born while the family lived at an apparently unaffected residence. However, the initial exposure status of all subjects was considered tentative until more extensive exposure assessments were completed, as described below.

Birth certificates were reviewed to obtain information on the family, including the full names of the subject and parents; the subject's date of birth, birth weight and gestational duration; and the parents' ages and educational levels at the subject's birth. The study was approved by the Institutional Review Boards of the Massachusetts Department of Public Health and Boston University Medical Center and by the 24A/B/11B Review Committee at the Massachusetts Department of Public Health. 


\section{Follow-up and enrollment}

Follow-up and enrollment occurred during 2006-2008. As described in Table 1, 6.6\% of the selected population could not be located $(\mathrm{n}=332), 45.5 \%$ were located but never responded to our contact attempts $(n=2,294)$, $3.7 \%$ refused to participate $(n=187)$, and $2.2 \%$ were deceased $(n=111)$. The Massachusetts Department of Public Health IRB did not allow us to contact another $8.5 \%$ of subjects whose parent had refused to participate in our prior cohort study of reproductive and developmental outcomes $(n=427)$ [15]. These percentages were similar for both exposed and unexposed subjects and their older siblings.

Available birth certificate and water distribution data also indicated that participants and non-participants were similar with respect to their initial PCE exposure status $(36.7 \%$ and $38.8 \%$ of participants and nonparticipants were considered exposed), race (98.5\% and $97.3 \%$, respectively, were White), mean age (29.3 and 28.9 years, respectively, as of June 30,2007$)$, mean duration of gestation (40.1 and 39.9 weeks, respectively), and mean birth weight (3,428 and 3,401 grams, respectively). Participants were more likely to be female
(60.7\% of participants vs. $43.5 \%$ of non-participants), and have mothers with some college education $(61.0 \%$ of participants vs. $49.3 \%$ of non-participants); however, these differences were present for both exposed and unexposed non-participants.

A self-administered questionnaire was sent to all successfully traced subjects to gather information on height and weight (to estimate body mass index), and chronic conditions, including diagnoses of cancer; diabetes; hypertension; cardiovascular disease; epilepsy and seizure disorders; stroke, mini stroke and transient ischemic attack; multiple sclerosis; lupus; amyotrophic lateral sclerosis; Huntington's disease; Parkinson's disease; rheumatoid arthritis; scleroderma; and vision impairment resulting from blindness, color blindness, glaucoma, macular degeneration, cataracts, far sightedness and near sightedness. All disease-related questions asked if a doctor or health care provider had ever stated that the participant had a particular condition and what year the condition was diagnosed. Respondents were also asked to rate their own overall health (i.e., excellent, very good, good, fair and poor) and in comparison to other people their own age (i.e., better than most, about the same, and worse than most).

Table 1 Selection, enrollment, and initial and final exposure status of study subjects

\begin{tabular}{|c|c|c|c|c|}
\hline & \multicolumn{3}{|c|}{ Initial exposure status } & \multirow[b]{3}{*}{ Total } \\
\hline & \multicolumn{2}{|c|}{ Index subject } & \multirow{2}{*}{$\begin{array}{l}\text { Older sibling } \\
\text { Unexposed }\end{array}$} & \\
\hline & Exposed & Unexposed & & \\
\hline Selected & 1910 & 1928 & 1202 & 5040 \\
\hline \multicolumn{5}{|l|}{ Excluded during enrollment } \\
\hline Deceased & 35 & 40 & 36 & 111 \\
\hline Parent refused participation & 199 & 148 & 80 & 427 \\
\hline Never located & 113 & 149 & 70 & 332 \\
\hline No response & 871 & 887 & 536 & 2294 \\
\hline Refused & 73 & 78 & 36 & 187 \\
\hline Returned questionnaire & 619 & 626 & 444 & 1689 \\
\hline Percent of selected & $32.4 \%$ & $32.5 \%$ & $36.9 \%$ & $33.5 \%$ \\
\hline Percent of located & $39.6 \%$ & $39.3 \%$ & $43.7 \%$ & $40.5 \%$ \\
\hline \multicolumn{5}{|c|}{ Excluded during exposure assessment } \\
\hline Inadequate residential history & 15 & 37 & 29 & 81 \\
\hline Off-Cape address in potential & 19 & 27 & 50 & 96 \\
\hline \multicolumn{5}{|l|}{$\mathrm{VL} / \mathrm{AC}$ town } \\
\hline Available for analysis & 585 & 562 & 365 & 1512 \\
\hline Percent of selected & $30.6 \%$ & $29.1 \%$ & $30.4 \%$ & $30.0 \%$ \\
\hline \multicolumn{5}{|l|}{ Final exposure status } \\
\hline Both prenatal and early & 561 & 160 & 110 & 831 \\
\hline \multicolumn{5}{|l|}{ childhood exposure } \\
\hline Only early childhood & 7 & 42 & 85 & 134 \\
\hline \multicolumn{5}{|l|}{ Exposure } \\
\hline Unexposed & 17 & 360 & 170 & 547 \\
\hline
\end{tabular}


Information was also gathered on demographic characteristics; family history of cancer and other relevant diseases; health-related behaviors such as cigarette smoking, alcoholic beverage consumption and illicit drug use; occupational and non-occupational exposure to solvents; and residential addresses from birth through 1990. Lastly, the survey gathered information on the subject's knowledge of the PCE contamination episode and self-assessments of PCE exposure. Additional questionnaire data on maternal characteristics and behaviors during the prenatal period and certain health outcomes (e.g. cancer) were available for subjects whose mothers participated in our prior cohort study on the impact of PCE exposure on reproduction and development. Information on the mother's water use patterns was available for only $58 \%$ of subjects and the prevalence of key variables was relatively low (e.g., bottled water use) and so these data were omitted from our analyses.

\section{Geocoding of residential addresses}

Approximately $95 \%$ of reported addresses were successfully geocoded using ArcGIS 8, and all geocoding was conducted without knowledge of the exposure or outcome status. In most instances, each address was geocoded to a parcel of land. Addresses that could not be geocoded to a specific parcel were geocoded to the closest parcel by street number. If a street number was unavailable and the street was less than a mile long, the address was geocoded to the middle of the street. If the street was a mile or longer, the address was geocoded to the intersection of the street with the cross-street provided in the survey.

\section{PCE exposure assessment}

As previously described, a tentative exposure status was assigned to each subject by visually inspecting maps of the pipe distribution network in the area surrounding the birth residence. To determine the final exposure designation, we used a more extensive exposure assessment model to estimate the mass of PCE delivered to each residence from the prenatal period through five years of age.

\section{The Webler-Brown Model and EPANET}

The leaching and transport model, which was developed by Webler and Brown for our prior epidemiological studies [16,17], estimates the quantity of PCE entering the drinking water using the initial amount of PCE in the liner (based on the pipe diameter and length), the age of the pipe, and the leaching rate of PCE from the liner into the water. Information on the locations, installation dates and diameters of all VL/AC pipes in the public water supplies was provided by local water departments and the Massachusetts Department of Environmental Protection
(DEP). According to by laboratory experiments by Demond, the leaching process followed a simple exponential relationship [2].

The transport algorithm requires an estimate of water flow rate and direction, which are functions of the configuration of the pipes and number of water users. The present study incorporated the Webler and Brown algorithm into the publically available source code of EPANET water distribution modeling software which characterizes water flow throughout a town's entire public distribution system [18]. EPANET, which was developed by the US EPA for water monitoring programs, has been also applied in epidemiological studies by others to assess the health effects of drinking water contaminants $[19,20]$.

\section{GIS together with the models}

In the first step of the exposure assessment process, we created GIS layers depicting the subject residences, water sources, pipe characteristics, and nodes, that represented points of water consumption along the pipe. Data on the location, installation date, and diameter of $\mathrm{VL} / \mathrm{AC}$ pipes was obtained from local water companies and the Massachusetts Department of Environmental Protection. The GIS represented the pipe configuration in the period around 1980.

Next, we used EPANET to simulate the instantaneous flow of water through each town's network and to estimate the annual mass of PCE delivered to each point on the network or node and all subject residences associated with the node. We assumed that all land parcels represented water users, all water users in the network drew the same quantity of water, and water sources did not change over the study period. These assumptions are supported by observations that the study area was mainly comprised of residences, and the distribution system changed little between the late 1960s and late 1980 s, when some water sources were added to accommodate population growth.

Only annual PCE exposures were calculated because only move-in and pipe installation years were available. We estimated PCE exposure during the prenatal period by multiplying the annual mass of PCE that entered the subject's residence during their birth year by $9 / 12$. We estimated cumulative exposure during early childhood by summing the estimated mass of PCE that entered their residences from the month and year following birth through the month and year of the fifth birthday. Simple proportions were used to account for partial years.

PCE exposure levels were estimated only for subjects who had complete geocoded residential histories from birth through age five. This excluded 81subjects because they had inadequate residential histories (Table 1). For practical reasons, another 96 subjects were excluded 
because at least one of their residences was in an offCape town with some VL/AC pipe and our extensive PCE exposure assessments were limited to Cape Cod. Subjects who reported living in a Cape Cod town without any VL/AC pipes $(n=7)$ were assumed to have no PCE exposure at that address because available records indicated little or no PCE contamination of these water sources.

\section{Statistical analysis}

We compared the occurrence of each chronic condition among subjects with combined prenatal and early childhood exposure to unexposed subjects. First, we examined the impact of any PCE and then divided the exposure at the median to examine whether risk was related to higher or lower level of exposure. Nearly all subjects with prenatal exposure also had childhood exposure and so we were unable to examine the impact of prenatal exposure only. In addition, we did not examine the impact of exposure only during childhood because there were too few subjects in this category $(n=134)$ to provide stable effect estimates of the outcomes under investigation.

The risk ratio (RR) was used to estimate the strength of the association between PCE exposure and the occurrence of each chronic condition. Ninety-five percent confidence intervals were used to assess the precision of the risk ratios. Generalized estimating equation (GEE) analyses were performed to account for nonindependent outcomes arising from several children from the same family $[21,22]$. The log link was used while assuming equal correlation between birth outcomes from the same mother. These analyses were performed only if there were at least five exposed and five unexposed participants who reported a particular health outcome.

Adjusted GEE analyses were conducted to assess the influence of confounding. Variables considered for these analyses were demographic, medical and family characteristics, and non-drinking water sources of solvent exposure. These variables included the subject's gender, race, age, educational level, employment status, and marital status; cigarette smoking, alcoholic beverage consumption and illicit drug use; history of solventrelated jobs and hobbies; family history of cancer and other diseases; parental characteristics and behaviors during the subject's pregnancy, and a history of head trauma (for analyses of epilepsy). Each of these variables was added to the GEE model one at a time to assess the presence of confounding. Most of the potential confounding variables had very little missing data and so individuals with missing data were dropped from these analyses. Only age had a meaningful impact ( $>10 \%$ change) in the crude estimates of associations and so this was the only variable included in the final adjusted GEE model.

\section{Results}

A total of 1,512 subjects were available for the analysis. According to the initial exposure designation, there were 585 exposed and 562 unexposed index subjects and 365 unexposed older siblings (Table 1). Following the more refined exposure assessment, approximately $27.4 \%$ of subjects $(\mathrm{N}=414)$ changed their status during the detailed exposure assessment either because (1) their birth address was further downstream from a VL/AC pipe than was considered exposed in the preliminary visual assessment, (2) their modeled assessment indicated a different water flow direction than was originally assumed, (3) their questionnaire data indicated that they used a private wells, or (4) their questionnaire data indicated that they lived in an affected residence during childhood. Thus, the final analytic groups were comprised of 831 subjects with prenatal and early childhood exposure and 547 subjects with no exposure during either period. As previously mentioned, 134 subjects with only childhood exposure were excluded from the analysis.

As shown in Table 2, the characteristics of the exposed and unexposed subjects were quite similar. Subjects were predominantly female, white, college-educated, in their late 20s, married or cohabitating, and employed when they completed the study questionnaires. Few subjects had possible occupational exposure to solvents but many had potential exposure from hobbies and other sources. Family history of relevant illnesses, parental characteristics, and the frequency of cigarette smoking, and alcoholic beverage consumption was also similar across groups; however, the frequency of illicit drug use (e.g., crack, cocaine, psychedelics/hallucinogens, club/designer drugs, Ritalin without a prescription, and heroin) was more common among exposed participants [14].

The study population was exposed to a wide distribution of PCE exposure levels that covered several orders of magnitude. Cumulative prenatal exposure levels were lower than early childhood levels because of their different durations (nine months vs. five years). Mean (SD) exposures were 32.6 (88.6), 109.0 (283.3), and 141.6 (358.1) grams, respectively, for prenatal, early childhood and combined prenatal and early childhood exposure.

When we compared each subject's self-assessed exposure status to that derived from the modeled assessment, we found that only $7 \%$ of subjects considered exposed by the modeled assessment thought that their drinking water was contaminated, whereas $29 \%$ of these exposed subjects thought that their water was not contaminated and $64 \%$ were unsure. Similarly, we found that $31 \%$ of subjects considered unexposed by the modeled assessment thought that their drinking water was not contaminated 
Table 2 Distribution of selected characteristics of subjects and parents by PCE exposure status

\begin{tabular}{|c|c|c|c|c|}
\hline \multirow[t]{3}{*}{ Characteristic } & \multicolumn{2}{|c|}{ Prenatal and early childhood exposure } & \multirow{2}{*}{\multicolumn{2}{|c|}{$\frac{\text { Unexposed }}{(\mathrm{N}=547)}$}} \\
\hline & \multicolumn{2}{|c|}{$(\mathrm{N}=831)$} & & \\
\hline & $\mathrm{n}$ & $\%$ & $\mathrm{n}$ & $\%$ \\
\hline Current age ( $n$, mean, sd) & 831 & $29.2(3.6)$ & 547 & $29.6(3.8)$ \\
\hline \multicolumn{5}{|l|}{ Gender } \\
\hline Male & 331 & 39.8 & 216 & 39.5 \\
\hline Female & 500 & 60.2 & 331 & 60.5 \\
\hline$\%$ White race & 818 & 98.4 & 539 & 98.5 \\
\hline \multicolumn{5}{|l|}{ Current educational level } \\
\hline High school graduate or less & 128 & 15.4 & 67 & 12.2 \\
\hline Some college & 192 & 23.1 & 144 & 26.3 \\
\hline Four year college grad or higher & 510 & 61.4 & 335 & 61.2 \\
\hline Missing & 1 & 0.1 & 1 & 0.2 \\
\hline \multicolumn{5}{|l|}{ Currently employed } \\
\hline Yes & 719 & 86.5 & 487 & 89.0 \\
\hline No & 92 & 11.1 & 54 & 9.9 \\
\hline Missing & 20 & 2.4 & 6 & 1.1 \\
\hline \multicolumn{5}{|l|}{ Current marital status } \\
\hline Single & 272 & 32.7 & 157 & 28.7 \\
\hline Married or cohabitating & 536 & 64.5 & 371 & 67.8 \\
\hline Other & 19 & 2.3 & 12 & 2.2 \\
\hline Missing & 4 & 0.5 & 7 & 1.3 \\
\hline \multicolumn{5}{|l|}{ Ever had solvent-exposed job } \\
\hline Yes & 123 & 14.8 & 71 & 13.0 \\
\hline No & 687 & 82.7 & 461 & 84.3 \\
\hline Missing & 21 & 2.5 & 15 & 2.7 \\
\hline \multicolumn{5}{|l|}{ Ever had solvent-exposed hobby } \\
\hline Yes & 700 & 84.2 & 462 & 84.5 \\
\hline No & 124 & 14.9 & 79 & 14.4 \\
\hline Missing & 7 & 0.8 & 6 & 1.1 \\
\hline \multicolumn{5}{|l|}{ Cigarette smoking history } \\
\hline Current & 194 & 23.3 & 104 & 19.0 \\
\hline Former & 180 & 21.7 & 134 & 24.5 \\
\hline Never & 451 & 54.3 & 308 & 56.3 \\
\hline Missing & 6 & 0.7 & 1 & 0.2 \\
\hline \multicolumn{5}{|c|}{ Current alcoholic beverage consumption } \\
\hline$>8$ days per month & 256 & 30.8 & 181 & 33.1 \\
\hline$<=8$ days per month & 413 & 49.7 & 255 & 46.6 \\
\hline Non-drinker & 149 & 17.9 & 108 & 19.7 \\
\hline Missing & 13 & 1.6 & 3 & 0.5 \\
\hline \multicolumn{5}{|l|}{ Current major $^{a}$ drug use } \\
\hline Yes & 289 & 34.8 & 162 & 29.6 \\
\hline No & 530 & 63.8 & 380 & 69.5 \\
\hline Missing & 12 & 1.4 & 5 & 0.9 \\
\hline Mother's age $(\mathrm{n}$, mean $(\mathrm{sd}))$ & 831 & $27.2(4.7)$ & 547 & $27.5(4.4)$ \\
\hline
\end{tabular}


Table 2 Distribution of selected characteristics of subjects and parents by PCE exposure status (Continued)

\begin{tabular}{|c|c|c|c|c|}
\hline Father's age ${ }^{\mathrm{b}}(\mathrm{n}$, mean $(\mathrm{sd}))$ & 831 & $29.8(5.7)$ & 547 & $29.8(5.3)$ \\
\hline \multicolumn{5}{|l|}{ Mother's educational level ${ }^{b}$} \\
\hline High school graduate or less & 327 & 39.4 & 178 & 32.5 \\
\hline Some college & 243 & 29.2 & 188 & 34.4 \\
\hline Four year college grad or higher & 260 & 31.3 & 180 & 32.9 \\
\hline Missing & 1 & 0.1 & 1 & 0.2 \\
\hline \multicolumn{5}{|l|}{ Father's occupation ${ }^{\text {b }}$} \\
\hline White collar & 420 & 50.5 & 257 & 47.0 \\
\hline Blue collar & 275 & 33.1 & 170 & 31.1 \\
\hline Other & 126 & 15.2 & 112 & 20.5 \\
\hline Missing & 10 & 1.2 & 8 & 1.5 \\
\hline \multicolumn{5}{|l|}{ Mother received prenatal care ${ }^{b}$} \\
\hline Yes & 794 & 95.5 & 520 & 95.1 \\
\hline No & 4 & 0.5 & 0 & 0.0 \\
\hline Missing & 33 & 4.0 & 27 & 4.9 \\
\hline \multicolumn{5}{|l|}{ Mother smoked cigarettes ${ }^{\mathrm{b}}$} \\
\hline Yes & 182 & 21.9 & 113 & 20.7 \\
\hline No & 483 & 58.1 & 330 & 60.3 \\
\hline Missing & 166 & 20.0 & 104 & 19.0 \\
\hline \multicolumn{5}{|l|}{ Mother drank alcoholic beverages ${ }^{\mathrm{b}}$} \\
\hline Yes & 302 & 36.3 & 201 & 36.7 \\
\hline No & 361 & 43.4 & 242 & 44.2 \\
\hline Missing & 168 & 20.2 & 104 & 19.0 \\
\hline \multicolumn{5}{|l|}{ Mother had medical and obstetrical complications ${ }^{\mathrm{b}}$} \\
\hline Yes & 122 & 14.7 & 108 & 19.7 \\
\hline No & 536 & 64.5 & 331 & 60.5 \\
\hline Missing & 173 & 20.8 & 108 & 19.7 \\
\hline \multicolumn{5}{|l|}{ Mother had occupational exposure to solvents } \\
\hline Yes & 76 & 9.1 & 51 & 9.3 \\
\hline No & 573 & 69.0 & 381 & 69.7 \\
\hline Missing & 182 & 21.9 & 115 & 21.0 \\
\hline Subject's birth weight ( $\mathrm{n}$, mean, $(\mathrm{sd}))$ & 823 & $3,443(506)$ & 499 & $3,414(534)$ \\
\hline Subject's gestational age ( $\mathrm{n}$, mean, $(\mathrm{sd})$ ) & 790 & $40.1(2.5)$ & 516 & $39.9(2.4)$ \\
\hline Family history of cancer & 225 & 27.1 & 141 & 25.8 \\
\hline Family history of epilepsy or seizure disorder & 39 & 4.7 & 23 & 4.2 \\
\hline Family history of rheumatoid arthritis & 64 & 7.7 & 41 & 7.5 \\
\hline Family history of blindness & 11 & 1.3 & 6 & 1.1 \\
\hline Family history of color blindness & 64 & 7.7 & 45 & 8.2 \\
\hline Family history of dry eyes & 60 & 7.2 & 39 & 7.1 \\
\hline Family history of correctable ${ }^{c}$ vision impairment & 786 & 94.6 & 514 & 94.0 \\
\hline
\end{tabular}

${ }^{a}$ Major drugs include inhalants, cocaine, crack, psychedelics, hallucinogens, club drugs, designer drugs, heroin, and Ritalin without a prescription.

${ }^{b}$ At subject's birth or during subject's gestation.

${ }^{c}$ Correctable with eyeglasses or contact lenses. 
while $5 \%$ thought that their drinking water was contaminated and $63 \%$ were unsure.

The relationship between early life PCE exposure and self-reported health outcomes is described below and summarized in Table 3. Compared to unexposed subjects, twice as many exposed subjects considered themselves to be in fair or poor health (4.5\% versus $2.2 \%)$ and nearly three times as many exposed subjects considered their health to be worse than most people their own age (7.1\% versus $2.6 \%$ ).

In line with these self-assessments, individuals with early life PCE exposure had a 1.8-fold increased risk of cancer (95\% CI: $0.8,4.0)$. This finding was based on 31 cancer cases (23 exposed and 8 unexposed) who reported a wide variety of cancers diagnosed between ages 4 and 32 years (median age at diagnosis $=25$ years) (Table 4). Notably, a history of early life PCE exposure was present for all five reported cases of cervical cancer, both reported cases of brain cancer, and eleven of the thirteen cases who reported a wide variety skin cancer cases (including melanoma, basal cell carcinoma, squamous cell carcinoma and skin cancer not otherwise specified). A 2.8-fold increased risk of all skin cancers combined was observed in relation to early life PCE exposure (95\% CI: 0.6, 13.0). Risk ratios for other cancer sites were not estimated because of the small number of cases.

Regarding the non-cancer outcomes, individuals with any early life PCE exposure also had a 1.5 -fold increased risk of epilepsy $(95 \%$ CI: $0.6,3.6)$ that was further increased to 1.8 (95\% CI: 0.7, 4.6) among individuals with exposure at or above the sample median (Table 3). The age of diagnosis among the epilepsy cases ranged from infancy to 24 years (median age at diagnosis $=17.5$ years). In contrast, no associations were observed between early life PCE exposure and the occurrence of obesity, diabetes, cardiovascular disease, hypertension, color blindness, near- and far sightedness and dry eyes. The frequency of the remaining illnesses was too rare to calculate stable measures of association: stroke, mini stroke or transient ischemic attack ( $\mathrm{n}=6$ overall); lupus $(\mathrm{n}=3)$; multiple sclerosis $(n=5)$; amyotrophic lateral sclerosis $(\mathrm{n}=1)$, scleroderma $(\mathrm{n}=0)$, Huntington's disease $(\mathrm{n}=0)$, Parkinson's disease $(n=0)$, rheumatoid arthritis $(n=15)$, deafness $(n=6)$, blindness $(n=12)$, cataracts $(n=6)$, glaucoma $(n=1)$, and macular degeneration $(n=2)$.

\section{Discussion}

While the number of cases was small, the results of this study suggest that individuals with early life exposure to PCE-contaminated drinking water may have an increased risk of epilepsy and certain types of cancer, particularly cervical cancer. No increases in risk were observed for obesity, diabetes, cardiovascular disease, hypertension, and clinically evident vision abnormalities.

These findings should be interpreted cautiously in light of several limitations. First, the young age of the participants (mean ages were 29.6 and 29.2 years for exposed and unexposed subjects, respectively) meant that the frequency of many chronic conditions was low, including cancers linked to PCE exposure in previous occupational and drinking water studies [5]. While the prevalence of epilepsy, diabetes and other conditions was similar to national estimates for this age group $[23,24]$, it is likely that the use of selfreported information on health outcomes resulted in some inaccurate information stemming from underreporting, over-reporting or mis-reporting diagnoses. However, since most subjects did not know their exposure status we believe that the resulting outcome misclassification would not have affected the risk ratios or would have biased them towards the null [25].

The findings are also likely affected by exposure misclassification. Because historical exposure measurements were unavailable, we estimated PCE exposure using a leaching and transport model $[16,17]$. The model was applied to water distribution system conditions in 1980 and was assumed to be representative of the entire exposure period. Furthermore, the exposure assessment predicted the annual mass of PCE delivered to each subject's residence during gestation and early childhood. Because information on maternal water use was available for only $58 \%$ of the study population, we did not incorporate these behavioral data into our analyses. While results from validation studies indicate reasonable correlation between our exposure estimates and PCE concentrations in historical water samples (Spearman correlation coefficient $=0.65$, $\mathrm{p}<0.00010$ ) [26], non-differential exposure misclassification likely biased the findings from dichotomous comparisons (e.g., any exposure vs. none) towards the null [27]. The expected direction of bias for comparisons involving the exposure levels is more difficult to predict but associations seen among subjects in the highest tertile are likely to be attenuated while those in the middle category could have either an upward or downward bias.

Still another limitation stems from possible residual confounding from missing data on risk factors for the outcomes under study. However, in order to account for the associations observed in this study, these factors would need to be tightly correlated with PCE exposure, an unlikely scenario given the irregular pattern of the PCE contamination across the neighborhoods of Cape Cod. In fact, our prior studies of this cohort found little or no confounding when other health outcomes were examined [15,28]. 
Table 3 Prenatal and early childhood exposure to tetrachloroethylene and the risk of chronic health conditions

\begin{tabular}{|c|c|c|c|c|}
\hline \multirow[t]{3}{*}{ Health outcome } & Exposure & $\%$ Yes $(n / N)$ & \multirow{3}{*}{$\begin{array}{l}\text { Crude GEE } \\
\text { Risk ratio } \\
(95 \% \mathrm{Cl})\end{array}$} & \multirow{3}{*}{$\begin{array}{l}\text { Adjusted GEE } \\
\text { Risk ratio } \\
(95 \% \mathrm{Cl})\end{array}$} \\
\hline & Category/ & & & \\
\hline & Percentile & & & \\
\hline \multirow[t]{4}{*}{ Cancer } & Any & $2.8(23 / 828)$ & $1.9(0.9,4.2)$ & $1.8(0.8,4.0)$ \\
\hline & $>=50^{\text {th }}$ & $2.9(12 / 415)$ & $2.0(0.8,4.8)$ & $1.7(0.7,4.5)$ \\
\hline & $>0-<50^{\text {th }}$ & $2.7(11 / 413)$ & $1.8(0.7,4.5)$ & $1.9(0.7,4.8)$ \\
\hline & None & $1.5(8 / 545)$ & Reference & Reference \\
\hline \multirow[t]{4}{*}{ Diabetes } & Any & $1.2(10 / 828)$ & $0.9(0.4,2.5)$ & $1.0(0.4,2.6)$ \\
\hline & $>=50^{\text {th }}$ & $1.2(5 / 415)$ & $0.9(0.3,2.9)$ & $0.9(0.3,2.7)$ \\
\hline & $>0-<50^{\text {th }}$ & $1.2(5 / 413)$ & $0.9(0.3,2.9)$ & $1.1(0.3,4.2)$ \\
\hline & None & $1.3(7 / 544)$ & Reference & Reference \\
\hline \multirow[t]{4}{*}{ Hypertension } & Any & $8.5(70 / 824)$ & $1.2(0.8,1.8)$ & $1.2(0.8,1.8)$ \\
\hline & $>=50^{\text {th }}$ & $8.2(34 / 414)$ & $1.2(0.8,1.8)$ & $1.1(0.7,1.7)$ \\
\hline & $>0-<50^{\text {th }}$ & $8.8(36 / 410)$ & $1.3(0.8,1.9)$ & $1.4(0.9,2.2)$ \\
\hline & None & $7.0(38 / 543)$ & Reference & Reference \\
\hline \multirow[t]{4}{*}{ Cardiovascular Disease } & Any & $0.6(5 / 825)$ & $0.4(0.1,1.2)$ & $1.5(0.6,3.6)$ \\
\hline & $>=50^{\text {th }}$ & $0.5(2 / 414)$ & ----- & ----- \\
\hline & $>0-<50^{\text {th }}$ & $0.7(3 / 411)$ & ---- & ----- \\
\hline & None & $1.5(8 / 541)$ & Reference & Reference \\
\hline \multirow[t]{4}{*}{ Epilepsy } & Any & $1.9(16 / 826)$ & $1.5(0.6,3.6)$ & $1.5(0.6,3.6)$ \\
\hline & $>=50^{\text {th }}$ & $2.2(9 / 415)$ & $1.7(0.6,4.5)$ & $1.8(0.7,4.6)$ \\
\hline & $>0-<50^{\text {th }}$ & $1.7(7 / 411)$ & $1.3(0.5,3.7)$ & $1.2(0.4,3.5)$ \\
\hline & None & $1.3(7 / 543)$ & Reference & Reference \\
\hline \multirow[t]{4}{*}{ Obesity } & Any & $24.7(138 / 558)$ & $0.9(0.7,1.2)$ & $0.9(0.7,1.2)$ \\
\hline & $>=50^{\text {th }}$ & $26.0(71 / 273)$ & $1.0(0.7,1.3)$ & $1.0(0.7,1.3)$ \\
\hline & $>0-<50^{\text {th }}$ & $23.5(67 / 285)$ & $0.9(0.7-1.2)$ & $0.9(0.7,1.2)$ \\
\hline & None & $26.7(92 / 344)$ & Reference & Reference \\
\hline \multirow[t]{4}{*}{ Color blindness } & Any & $1.4(11 / 779)$ & $0.6(0.3,1.3)$ & $0.6(0.3,1.3)$ \\
\hline & $>=50^{\text {th }}$ & $1.0(4 / 386)$ & ----- & ----- \\
\hline & $>0-<50^{\text {th }}$ & $1.8(7 / 393)$ & $0.7(0.3,1.8)$ & $0.8(0.3,2.2)$ \\
\hline & None & $2.5(13 / 528)$ & Reference & Reference \\
\hline \multirow[t]{4}{*}{ Near sightedness } & Any & $22.1(171 / 775)$ & $1.0(0.8,1.2)$ & $1.0(0.8,1.2)$ \\
\hline & $>=50^{\text {th }}$ & $21.6(83 / 385)$ & $1.0(0.7,1.2)$ & $0.9(0.7,1.2)$ \\
\hline & $>0-<50^{\text {th }}$ & $22.6(88 / 390)$ & $1.0(0.8,1.3)$ & $1.0(0.8,1.3)$ \\
\hline & None & $22.6(118 / 523)$ & Reference & Reference \\
\hline \multirow[t]{4}{*}{ Far sightedness } & Any & $55.6(429 / 771)$ & $1.0(0.9,1.1)$ & $1.0(0.9,1.1)$ \\
\hline & $>=50^{\text {th }}$ & $56.4(215 / 381)$ & $1.0(0.9,1.1)$ & $0.9(0.8,1.1)$ \\
\hline & $>0-<50^{\text {th }}$ & $54.9(214 / 390)$ & $0.9(0.8,1.1)$ & $1.0(0.9,1.1)$ \\
\hline & None & $58.3(307 / 527)$ & Reference & Reference \\
\hline \multirow[t]{4}{*}{ Dry eyes } & Any & $8.4(65 / 775)$ & $1.2(0.8,1.8)$ & $1.2(0.8,1.8)$ \\
\hline & $>=50^{\text {th }}$ & $8.8(34 / 386)$ & $1.3(0.8,2.0)$ & $1.2(0.8,1.9)$ \\
\hline & $>0-<50^{\text {th }}$ & $8.0(31 / 389)$ & $1.1(0.7,1.8)$ & $1.3(0.8,2.0)$ \\
\hline & None & $7.0(37 / 528)$ & Reference & Reference \\
\hline
\end{tabular}




\begin{tabular}{|c|c|c|c|}
\hline Cancer site/type & $\begin{array}{l}\text { Total } \\
\text { number }\end{array}$ & $\begin{array}{l}\text { Number with any } \\
\text { exposure }\end{array}$ & $\begin{array}{l}\text { Number } \\
\text { unexposed }\end{array}$ \\
\hline Cervix & 5 & 5 & 0 \\
\hline Ovary & 2 & 1 & 1 \\
\hline Testes & 2 & 0 & 2 \\
\hline Hodgkin lymphoma & 1 & 1 & 0 \\
\hline $\begin{array}{l}\text { Lymphoma, not } \\
\text { otherwise specified }\end{array}$ & 1 & 1 & 0 \\
\hline Leukemia & 1 & 1 & 0 \\
\hline Brain & 2 & 2 & 0 \\
\hline Thyroid & 2 & 0 & 2 \\
\hline Pancreas & 1 & 1 & 0 \\
\hline Sarcoma & 1 & 0 & 1 \\
\hline Melanoma & 4 & 4 & 0 \\
\hline $\begin{array}{l}\text { Other skin cancer (basal } \\
\text { or squamous) }\end{array}$ & 7 & 5 & 2 \\
\hline $\begin{array}{l}\text { Skin cancer, not } \\
\text { otherwise specified }\end{array}$ & 2 & 2 & 0 \\
\hline Total & 31 & 23 & 8 \\
\hline
\end{tabular}

A further limitation stems from the study's low response rate. Although this problem reduced the statistical power of the study, the following evidence suggests that it did not result in selection bias. First, most available characteristics of participants and non-participants were similar, including initial PCE exposure status, race, mother's age at delivery, and birth characteristics. Second, while participants were more likely to be female (60.7\% of participants vs. $43.5 \%$ of non-participants), and have mothers with some college education $(61.0 \%$ for participants vs. $49.3 \%$ for non-participants), these differences were equally present for exposed and unexposed non-participants. Third, losses stemming from the death of potential participants were small and unrelated to initial PCE exposure status $(\mathrm{n}=111$, Table 1$)$.

PCE's potential to cause cancer has been established through numerous animal and human studies that have contributed to PCE's designation as a "probable human carcinogen" by the International Agency for Cancer Research (IARC) and "likely to be carcinogenic in humans" by the US EPA $[5,6,29]$. Evidence comes from animal experiments where increases in mononuclear cell leukemia and kidney tumors among PCE-exposed rats and hepatocellular tumors, hemangiomas and hemangiosarcomas among PCE-exposed mice have been observed [6]. Evidence from human studies comes mainly from investigations of dry cleaners and other adults occupationally exposed to PCE and related solvents [30-32]. However, studies of adult exposure to PCE-contaminated drinking water have also contributed to the literature [33,34].
Taken together, epidemiological studies provide evidence for associations between adult PCE exposure and bladder cancer, non-Hodgkin lymphoma and multiple myeloma, and possibly cervical, esophageal, kidney, lung, liver and breast cancer $[5,6]$. To the best of our knowledge, there are little data on the risk of skin cancer following adult PCE exposure.

In contrast, the few epidemiological studies on the risk of cancer following early life exposure to solvents such as PCE have produced mixed results. One study found a null association between the occurrence of neuroblastoma among offspring and occupational exposure to PCE among mothers [35]. In contrast, three studies of childhood hematopoietic cancers have found positive associations. The largest of these studies found a 1.6-fold increased risk of acute lymphocytic leukemia (95\% CI:1.1-2.3) among children whose mothers worked with a variety of solvents during pregnancy [36]. Two additional small studies also found positive associations between prenatal exposure to drinking water contaminated with PCE, TCE and other solvents and either childhood leukemia alone or in combination with non Hodgkin lymphoma (OR: 8.3, 95\% CI: 0.7-94.7 from [37] and OR 1.6, 95\% CI: 0.5-4.8 from [38]). However, a large study of acute lymphoblastic leukemia found no association with maternal occupational exposure to PCE during pregnancy ([39], and a small study of childhood cancer found no association among residents' exposure to volatile organic compounds such as TCE and PCE through soil vapor intrusion into buildings [40].

In addition, even though neurotoxicity is considered a sensitive endpoint for assessing adverse health impacts of PCE exposure, the published literature on the risk of epilepsy following solvent exposure is sparse. To the best of our knowledge, only one epidemiological study has investigated the relationship between epilepsy and occupational exposure to organic solvents [41]. This Swedish case-control study found a 1.7-fold increased risk of epilepsy among individuals with any probable exposure to unspecified solvents $(\mathrm{p}=0.20)$ and a 4.4-fold increased risk among individuals with probable heavy solvent exposure $(p=0.05)$. These associations are supported by several case reports documenting the occurrence of seizures following occupational or recreational exposure to mixed solvents [42,43], trichloroethylene [44], and glues composed of toluene and xylene [45-48] among previously healthy adults and adolescents.

In summary, the results of the present study suggest that the risk of certain types of cancer such as cervical cancer and epilepsy may be increased among adults exposed to PCE during gestation and early childhood. These findings should be interpreted cautiously because of the study limitations and confirmed in follow-up investigations of similarly exposed populations that 
include medical confirmation of self-reported diseases. The study population should also be monitored periodically for any changes in disease risk in this relatively young population. Since PCE remains a commonly used commercial solvent that exposes workers and consumers and frequently contaminates drinking water, it is important to determine the long-term impact of early life exposure.

\section{Conclusions}

While adult exposure to PCE is known to have numerous toxic effects, there is little information on the longterm impact of prenatal and early childhood exposure. We undertook a retrospective cohort study to examine whether early life exposure to PCE-contaminated drinking water influenced the risk of a variety of chronic conditions among adults who were born in the Cape Cod area of Massachusetts. The results suggest that the risk of certain types of cancer such as cervical cancer and epilepsy may be increased among adults following PCE exposure during gestation and early childhood. No increases in the risk of obesity, diabetes, cardiovascular disease, hypertension, color blindness and other visual abnormalities were observed. These findings should be interpreted cautiously because of the study limitations and confirmed in follow-up investigations of similarly exposed populations that include medical confirmation of disease. The relatively young study population should also be monitored periodically for any changes in disease risk.

\section{Abbreviations}

Cl: Confidence Interval; DEP: Department of Environmental Protection; GEE: Generalized estimating equation; PCE: Tetrachloroethylene; RR: Risk Ratio; VL/AC: vinyl-lined asbestos-cement.

\section{Competing interests}

Dr. David Ozonoff is Co-editor-in-Chief of Environmental Health. At the request of the Commonwealth of Massachusetts, in 1980 Dr. Ozonoff was a witness in bankruptcy court in a suit against the Johns-Manville Corporation, manufacturers of the ACVL water mains. He has also, on occasion, testified in personal injury and property damage cases involving exposure to tetrachloroethylene and trichloroethylene.

\section{Authors' contributions}

AA conceived the study and its design, coordinated data collection and analysis, and drafted the initial manuscript. TW and W provided technical input to data collection, exposure assessment, data analysis, and manuscript preparation. MRW participated in the data collection and conducted the data analyses. DO, PAJ, LGG and JW provided technical input to the study design, data collection, and manuscript preparation. All authors read and approved the final manuscript.

\section{Acknowledgements}

The authors would like to acknowledge the study participants who took the time to share their experiences and the assistance of the local water companies and the Massachusetts Department of Environmental Protection. This work was supported by the National Institute of Environmental Health Sciences Superfund Research Program 5P42ES00738.

\section{Author details}

'Department of Epidemiology, Boston University School of Public Health, Talbot 3E, 715 Albany Street, Boston, MA 02118, USA. ²Data Coordinating Center, Boston University School of Public Health, Crosstown, 715 Albany Street, Boston, MA 02118, USA. ${ }^{3}$ University of California, Irvine, Program in Public Health, 653 East Peltason Dr, Irvine, CA 92697, USA. ${ }^{4}$ Department of Environmental Health, Boston University School of Public Health, Talbot 4 W 715 Albany Street, Boston, MA 02118, USA. ${ }^{5}$ Department of Biostatistics, Boston University School of Public Health, Crosstown, 715 Albany Street, Boston, MA 02118, USA.

Received: 10 October 2014 Accepted: 27 March 2015

Published online: 12 April 2015

\section{References}

1. Commonwealth of Massachusetts, Department of Environmental Quality Engineering: Status report on tetrachloroethylene contamination of public drinking water supplies caused by vinyl-lined asbestos cement pipe; 1982.

2. Demond $\mathrm{AH}$. A source of tetrachloroethylene in the drinking water of New England: an evaluation of toxicity of tetrachloroethylene and the prediction of its leaching rates from vinyl-lined asbestos-cement pipe. In: MS Thesis. Cambridge, MA: Massachusetts Institute of Technology; 1982.

3. Bove FJ, Fulcomer MC, Klotz JB, Esmart J, Dufficy EM, Savrin JE. Public drinking water contamination and birth outcomes. Am J Epidemiol. 1995;141:850-62

4. Sonnenfeld N, Hertz-Picciotto I, Kaye WE. Tetrachloroethylene in drinking water and birth outcomes at the US Marine Corps Base at Camp Lejeune, North Carolina. Am J Epidemiol. 2001;154:902-8.

5. U.S. Environmental Protection Agency. Toxicological Review of Tetrachloroethylene (Perchloroethylene). In: Support of Summary Information on the Integrated Risk Information System (IRIS). Washington DC: US EPA; 2012.

6. Guyton KZ, Hogan KA, Scott CS, Cooper GS, Bale AS, Kopylev L, et al. Human health effects of tetrachloroethylene: key findings and scientific issues. Environ Health Perspect. 2014;122:325-34.

7. Eskenazi BL, Gaylord L, Bracken MB, Brown D. In utero exposure to organic solvents and human neurodevelopment. Dev Med Child Neurol. 1988;30:492-501.

8. Spector J, Lewandowski AG, Mott JA, Schreiber JS. Neuropsychological and behavioral functioning in tetrachloroethylene-exposed preschool children and controls. Arch Clin Neuropsychol. 1999;14:661-2.

9. Till C, Koren G, Rovet JF. Prenatal exposure to organic solvents and child neurobehavioral performance. Neurotoxicol Teratol. 2001;23:235-45.

10. Laslo-Baker D, Barrera M, Knittel-Keren D, Kozer E, Wolpin J, Khattak S, et al. Child neurodevelopmental outcome and maternal occupational exposure to solvents. Arch Pediatr Adolesc Med. 2004;158:956-61.

11. Aschengrau A, Weinberg JM, Janulewicz PA, Romano ME, Gallagher LG, Winter MR, et al. Mental Illness Among Adults Following Prenatal and Childhood Exposure to Tetrachloroethylene (PCE)-contaminated Drinking Water. Environ Health. 2012;11:2.

12. Aschengrau A, Weinberg JM, Janulewicz PA, Romano ME, Gallagher LG, Winter MR, et al. Affinity for Risky Behaviors Following Prenatal and Childhood Exposure to Tetrachloroethylene (PCE)-contaminated Drinking Water. Environ Health. 2011;10:102.

13. Getz K, Janulewicz P, Rowe S, Weinberg J, Winter M, Martin B, et al. Visual Abnormalities Following Prenatal and Childhood Exposure to Tetrachloroethylene (PCE)-contaminated Drinking Water. Environ Health Perspect. 2012;120:1327-32.

14. Janulewicz P, White RF, Martin B, Winter MR, Weinberg JM, Vieira V, et al Adult Neuropsychological Performance Following Prenatal and Early Postnatal Exposure to Tetrachloroethylene (PCE)-contaminated Drinking Water. Neurotox Teratol. 2012;34:350-9.

15. Aschengrau A, Weinberg J, Rogers S, Gallagher L, Winter M, Vieira V, et al. Prenatal Exposure to Tetrachloroethylene-contaminated Drinking Water and the Risk of Adverse Birth Outcomes. Environ Health Perspect. 2008;116:814-20

16. Aschengrau A, Rogers S, Ozonoff D. Perchloroethylene-contaminated drinking water and the risk of breast cancer: additional results from Cape Cod, Massachusetts. Environ Health Perspect. 2003;111:167-73. 
17. Webler T, Brown HS. Exposure to tetrachloroethylene via contaminated drinking water pipes in Massachusetts: a predictive model. Arch Environ Health. 1993;48:293-7.

18. Rossman LA. EPANET users manual. Cincinnati, OH: U.S: Environmental Protection Agency, Risk Reduction Engineering Laboratory; 1994.

19. Maslia ML, Sautner JB, Aral MM, Reyes JJ, Abraham JE, Williams RC. Using water-distribution system modeling to assist epidemiologic investigations. Water Res Plan Mgmt. 2000;126:180-98.

20. Reif JS, Burch JB, Nuckols JR, Metzger L, Anger WK. Neurobehavioral effects of exposure to trichloroethylene through a municipal water supply. Environ Res. 2003;9:248-58.

21. Liang KY, Zeger SL. Longitudinal data analysis using generalized linear models. Biometrika. 1986;73:13-22.

22. Zeger SL, Liang KY. Longitudinal data analysis for discrete and continuous outcomes. Biometrics. 1986;42:121-30.

23. Centers for Disease Control and Prevention. Epilepsy in adults and access to care -United States. MMWR. 2012;61:909-13.

24. National Center for Health Statistics. Health. United States, 2012: With Special Feature on Emergency Care. Hyattsville, MD: National Center for Health Statistics; 2013.

25. Rothman KJ, Greenland S, Lash TL. Modern Epidemiology. 3rd ed. Philadelphia: Wolters Kluwer, Lippincott Williams and Wilkins; 2008.

26. Gallagher LG, Vieira VM, Ozonoff D, Webster TF, Aschengrau A. Risk of breast cancer following exposure to tetrachloroethylene-contaminated drinking water in Cape Cod. Massachusetts: reanalysis using a modified exposure assessment. Environ Health. 2011;19:47.

27. Aschengrau A, Seage GR. Essentials of Epidemiology in Public Health. 3rd ed. Burlington MA: Jones and Bartlett Learning; 2014.

28. Aschengrau A, Weinberg J, Gallagher L, Winter M, Vieira V, Webster T, et al. Prenatal Exposure to Tetrachloroethylene-contaminated Drinking Water and the Risk of Pregnancy Loss. Water Qual Expo Health. 2009;1:23-34.

29. International Agency for Cancer Research (IARC). Dry Cleaning, Some chlorinated Solvents, and Other Industrial Chemicals. IARC Monogr Eval Carcinog Risks Hum. 1995;63:159-221.

30. Antilla A, Pukkala E, Sallmen M, Hernberg S, Hemminki K. Cancer incidence among Finnish workers exposed to halogenated hydrocarbons. J Occup Environ Med. 1995;37:797-806.

31. Blair A, Petralia SA, Stewart PA. Extended mortality follow-up of a cohort of dry cleaners. Ann Epidemiol. 2003;13:50-6.

32. Gold LS, Stewart PA, Milliken K, Purdue M, Severson R, Seixas N, et al. The relationship between multiple myeloma and occupational exposure to six chlorinated solvents. Occup Environ Med. 2011:68:391-9.

33. Aschengrau A, Ozonoff D, Paulu C, Coogan P, Vezina R, Heeren T, et al Cancer risk and tetrachloroethylene-contaminated drinking water in Massachusetts. Arch Environ Health. 1993;148:284-92.

34. Paulu C, Aschengrau A, Ozonoff D. Tetrachloroethylene-contaminated drinking water in Massachusetts and the risk of colon-rectum, lung and other cancers. Environ Health Perspect. 1999;107:265-71.

35. De Roos AJ, Olshan AF, Teschke K, Poole C, Savitz DA, Blatt J, et al. Parental occupational exposures to chemicals and incidence of neuroblastoma in offspring. Am J Epidemiol. 2001;154:106-14.

36. Shu XO, Stewart P, Wen WQ, Han D, Potter JD, Buckley JD, et al. Parental occupational exposure to hydrocarbons and risk of acute lymphocytic leukemia in offspring. Cancer Epidemiol Biomarkers Prev. 1999;8:783-91.

37. Costas K, Knorr RS, Condon SK. A case-control study of childhood leukemia in Woburn, Massachusetts: the relationship between leukemia incidence and exposure to public drinking water. Sci Total Environ. 2002;300:23-35.

38. Ruckert PZ, Bove FJ, Maslia M. Evaluation of exposure to contaminated drinking water and specific birth defects and childhood cancers at Marine Corps Base Camp Lejeune. North Carolina: a case-control study. Environ Health. 2013:12:104.

39. Infante-Rivard C, Siemiatycki J, Lakhani R, Nadon L. Maternal exposure to occupational solvents and childhood leukemia. Environ Health Perspect. 2005;113:787-92.

40. Agency for Toxic Substances Disease Registry (ATSDR). Health Consultation In: Cancer and Birth Outcome Analysis. Endicott Area, Town of Union, Broome County, New York. Atlanta, GA: Agency for Toxic Substances and Disease Registry; 2006.

41. Littorin ME, Fehling C, Attewell RG, Skerfving S. Focal epilepsy and exposure to organic solvents: a case-referent study. J Occup Med. 1988:30:805-8.
42. Bernardini P, Scoppetta C. Exposure to solvents and tardy epilepsy: 2 clinical cases. Med Lav. 1992:83:266-73.

43. Jacobsen M, Baelum J, Bonde JP. Temporal epileptic seizures and occupational exposure to solvents. Occup Environ Med. 1994:51:429-30.

44. Sanz P, Nogue S, Vilchez D, Salvado E, Casal A, Logroscine G. Myoclonic encephalopathy after exposure to trichloroethylene. Ind Health. 2008;46:635-7.

45. Mutez E, Le Rhun E, Perriol MP, Soto Ares G, Pechuex N, Destee A, et al. Trichloroethylene intoxication presenting with temporal seizures. Rev Neurol. 2006;162:1248-51.

46. Helliwell M, Murphy M. Drug-induced neurological disease. Br Med J. 1979;1:1283-4.

47. Arthur $L H$, Curnock DA. Xylene-induced epilepsy following innocent glue sniffing. Br Med J. 1982;284:1787.

48. Allister C, Lush M, Oliver JS, Watson JM. Status epilepticus caused by solvent abuse. Br Med J. 1981;283:1156.

\section{Submit your next manuscript to BioMed Central and take full advantage of:}

- Convenient online submission

- Thorough peer review

- No space constraints or color figure charges

- Immediate publication on acceptance

- Inclusion in PubMed, CAS, Scopus and Google Scholar

- Research which is freely available for redistribution 